\title{
Major obstetric hemorrhage: a follow-up survey on quality of life of women and their partners
}

\section{Giel van Stralen, Laurine L. M. Ruijten, Ad A. Kaptein, Ron Wolterbeek \& Jos van Roosmalen}

To cite this article: Giel van Stralen, Laurine L. M. Ruijten, Ad A. Kaptein, Ron Wolterbeek \& Jos van Roosmalen (2017): Major obstetric hemorrhage: a follow-up survey on quality of life of women and their partners, Journal of Psychosomatic Obstetrics \& Gynecology, DOI: 10.1080/0167482X.2017.1286640

To link to this article: http://dx.doi.org/10.1080/0167482X.2017.1286640

\section{册 Published online: 09 Feb 2017.}

\section{Submit your article to this journal $\square$}

Џ Article views: 8

Q View related articles $\sqsubset$

View Crossmark data $\nearrow$ 


\title{
Major obstetric hemorrhage: a follow-up survey on quality of life of women and their partners
}

\author{
Giel van Stralen ${ }^{a}$, Laurine L. M. Ruijten ${ }^{b}$, Ad A. Kaptein ${ }^{c}$, Ron Wolterbeek ${ }^{d}$ and Jos van Roosmalen ${ }^{a}$ \\ ${ }^{a}$ Department of Obstetrics, Leiden University Medical Centre, Leiden, the Netherlands; ${ }^{b}$ Institute of Psychology, Erasmus University \\ Rotterdam, Rotterdam, the Netherlands; 'Section of Medical Psychology, Leiden University Medical Centre (LUMC), Leiden, the \\ Netherlands; ${ }^{d}$ Department of Medical Statistics, Leiden University Medical Centre (LUMC), Leiden, the Netherlands
}

ABSTRACT

Introduction: A description is given of the quality of life (QOL) of women who were treated with peripartum embolization or hysterectomy for major obstetric hemorrhage (MOH).

Methods: Questionnaires assessing QOL, combined with questionnaires and drawings assessing illness perceptions, were used to compare women with $\mathrm{MOH}$ to reference groups provided by the questionnaires.

Results: Women who experienced $\mathrm{MOH}$ have similar scores on QOL questionnaires compared to reference groups. Women treated with arterial embolization scored better than women treated with hysterectomy. Partners of women with $\mathrm{MOH}$ scored better on QOL questionnaires than reference groups. Drawings reflect the major emotional impact of $\mathrm{MOH}$.

Discussion: $\mathrm{MOH}$ does not seem to have a negative effect on QOL 6-8 years after the event, although drawings and verbalizations indicate major emotional impact. More extensive follow-up is advised for early recognition of the need for psychological help. Women after embolization seem to have better QOL compared to women after hysterectomy.
ARTICLE HISTORY

Received 15 April 2015

Revised 23 November 2016

Accepted 15 January 2017

\section{KEYWORDS}

Childbirth; mental health; obstetrics; psychological well-being; quality of life

\section{Introduction}

Major obstetric hemorrhage $(\mathrm{MOH})$ contributes to significant maternal morbidity and mortality [1]. Recent reports indicate that the incidence of postpartum hemorrhage (PPH) is increasing worldwide [2-13]. The physical impact of $\mathrm{MOH}$ has been studied extensively [14]; however hardly any data are available on psychological consequences. In 2010, a single unit study addressing quality of life (QOL) after uterine arterial embolization because of $\mathrm{MOH}$ was published [15]. Women in that study showed good QOL which most likely could be explained by "benefit finding": people who have experienced a traumatic event have the capacity to find benefits from the situation $[16,17]$. The psychological impact on partners of the studied women was underestimated, illustrated by a partner's comment: "I can still smell the blood" [15].

$\mathrm{QOL}$ is a multidimensional concept and describes the individual or group's well-being on several domains: physical, functional, psychological and social [18]. QOL fluctuates over time and focuses on patient's experiences and is therefore subjective. There is extensive evidence showing that illness perceptions influence QOL $[19,20]$. Illness perceptions consist of multiple components, which basically come down to the following questions: What is it? What causes it? What can I do about it? What can the physician do about it and how long will it last? [21].

The Common Sense Model (CSM) of self-regulation provides a theoretically based explanation for the relation between illness perceptions and QOL [22]. This model assumes that people's behavior is goal-directed and constantly monitored and adapted by the individual in order to reach these goals. Input for illness perceptions can be derived not only from individual experience but also from the media, doctors, or otherwise [20].

The current study was conducted to add QOL data to existing data on the psychological impact of $\mathrm{MOH}$ in a nationwide cohort. In addition, partners of the women were asked to participate by answering questions about their QOL.

\section{Methods}

This study is part of a 2-year nationwide cohort study that assessed severe acute maternal morbidity and

CONTACT Giel van Stralen gielvs@gmail.com Department of Obstetrics, Leiden University Medical Centre, P.0. Box 9600, 2300 RC Leiden, the Netherlands

(C) 2017 Informa UK Limited, trading as Taylor \& Francis Group 
mortality during pregnancy, delivery, and puerperium in the Netherlands [23]. Women were included nationwide from 98 hospitals with a maternity unit from 1 August 2004 until 1 August 2006. Detailed information about the data collection has been described previously [23]. An attempt to contact all women who experienced $\mathrm{MOH}(n=189)$, defined as peripartum hysterectomy or - embolization after a minimum gestational age of 24 completed weeks, was made between June 2012 and August 2013. All women and partners received a questionnaire at their home address via regular mail.

\section{Questionnaires}

The RAND-36, also known as the Short Form Health Survey (SF-36), is a questionnaire measuring QOL on a 0-100 scale in which a higher score reflects better outcome $[24,25]$. It consists of 36 items, classified in nine dimensions. Average scores of groups of respondents can be compared to the provided healthy reference groups which are subdivided by age and by gender.

The Brief Illness Perception Questionnaire (B-IPQ) is a nine-item questionnaire measuring patient's perceptions of a disease or medical condition [26,27]. The results of the questionnaire can be compared to five reference groups which are provided by the B-IPQ. We chose patients recovering from myocardial infarction because this is a comparable condition (short and potential life-threatening) and patients suffering from asthma because of comparable average age and better representation of women. Because of the shortcomings of the provided reference groups, Dutch patients with SLE (Systemic Lupus Erythematosus) were added as a reference group as described by Daleboudt et al. [28]. Furthermore, a patient survey was added, addressing women's and partners' experiences of the event and of hospital care and aspects of somatic recovery such as: lactation (problems) and recurrence of menstruational cycle and successive pregnancies (if applicable).

\section{Drawings}

Illness perceptions are usually assessed with questionnaires. A relatively new method to assess illness perceptions is through patients' drawings of affected organ(s) [21,28-33]. It has the advantage of circumventing possible social desirability issues and provides a unique and value free illustration of a person's illness perceptions [31]. All women were asked to retrospectively draw images of her uterus and pelvic area during the event (Drawing 1) and at the time of returning the questionnaires (Drawing 2). The area of the uterus and (remaining) internal genitals were measured by hand using graphical notebook paper. In addition, two authors (G. S. and L. R.) independently scored the drawings on degree of blood loss, degree of damage to the uterus, and psychological impact, using a 3-point scale. Congruity between scores was assessed by intraclass correlation coefficients. Mean scores of drawing 1 and drawing 2 were calculated and compared. This approach to illness perceptions scoring has been described earlier by Tiemensma et al. [31,33].

\section{Statistics}

Data were analyzed using SPSS 20.0 (IBM, Armonk, NY). Descriptive statistics were used to describe clinical parameters. Differences between scores of women and reference groups and scores of partners and reference groups were calculated and analyzed by using the onesample $t$-tests. Differences between means of two groups were analyzed with the independent-samples $t$ tests. Differences between dichotomous variables were analyzed with chi-square tests. Calculating intraclass correlation coefficients in a linear mixed model (oneway random ANOVA) assessed congruity between scores of G. S. and L. R. To examine the influence of illness perceptions on $\mathrm{QOL}$, correlations between questionnaire scores RAND-36 and B-IPQ were analyzed with Pearson's correlation coefficient. Closed survey questions were analyzed using descriptive statistics and the independent samples $t$-test. Open survey questions were analyzed and interpreted by G. S. and L. R. No corrections for multiple testing have been applied.

\section{Details of ethics approval}

Medical Ethics Commission of the Leiden University Medical Centre (LUMC) was obtained on 28 July 2010. Reference: CME-V 005.

\section{Results}

Questionnaires were filled in between June 2012 and August 2013, the range of the interval between the event and the completion of the questionnaires was 6-9 years. Table 1 describes characteristics of the 58 included women. Figure 1 describes selection and inclusion participants.

\section{RAND-36 (Table 2, Figure 2)}

Included women scored similar to gender- and agespecific reference groups except for four dimensions. 
Table 1. Characteristics of included women and women lost to follow-up (LTF).

\begin{tabular}{|c|c|c|c|c|c|}
\hline & $\begin{array}{l}\text { Included embolization } \\
\qquad n=24\end{array}$ & $\begin{array}{l}\text { Included hysterectomy } \\
\qquad n=34\end{array}$ & $p$ Values* & LTF embolization $n=66$ & LTF hysterectomy $n=65$ \\
\hline $\begin{array}{l}\text { Mean maternal age } \\
\text { (years) (range) }\end{array}$ & $33.1(26-40)$ & $33.8(22-42)$ & 0.49 & $31.0(20-45)$ & $34.8(23-44)$ \\
\hline BMI mean (range) & $22.5(20.1-25.7)$ & $24.4(18-46)$ & 0.26 & $23.4(17-35)$ & $24.4(17-43)$ \\
\hline $\begin{array}{l}\text { Weeks of gestation } \\
\text { (range) }\end{array}$ & $37+6(31+6$ to $40+6)$ & $38+3(26+3$ to $42+1)$ & 0.41 & $38+6(28+2$ to $42+1)$ & $38+1(26+5$ to $42+2)$ \\
\hline Prematurity $<37$ weeks & $4(17)$ & $7(20)$ & 0.75 & $10(15)$ & $15(23)$ \\
\hline Nulliparity & $16(67)$ & $9(26)$ & 0.01 & $40(61)$ & $11(17)$ \\
\hline Multiple pregnancy & $4(17)$ & $3(9)$ & 0.37 & $8(12)$ & $5(8)$ \\
\hline Previous cesarean & $2(8)$ & $16(47)$ & 0.02 & $6(9)$ & $27(41)$ \\
\hline Uterine rupture & 0 & $7(20)$ & 0.02 & $1(1)$ & $8(12)$ \\
\hline Placenta previa & $2(8)$ & $4(12)$ & 0.67 & $1(1)$ & $9(14)$ \\
\hline $\begin{array}{l}\text { Placenta accr/incr/ } \\
\text { percr** }\end{array}$ & $2(8)$ & $9(26)$ & 0.08 & $6(9)$ & $14(21)$ \\
\hline \multicolumn{6}{|l|}{ Mode of delivery } \\
\hline Spontaneous & $10(42)$ & $9(26)$ & 0.60 & $36(54)$ & $17(26)$ \\
\hline Ventouse & $4(17)$ & $5(15)$ & & $8(12)$ & $3(5)$ \\
\hline Planned cesarean & $6(25)$ & $11(32)$ & & $8(12)$ & $16(25)$ \\
\hline Emergency cesarean & $4(17)$ & $9(26)$ & & $14(22)$ & $29(45)$ \\
\hline $\begin{array}{l}\text { Mean total blood loss } \\
\text { (ml) (range) }\end{array}$ & $5797(1500-20,000)$ & $7478(1500-20,000)$ & 0.23 & 5050 & 6305 \\
\hline $\begin{array}{l}\text { Mean no of blood } \\
\text { products (range) }\end{array}$ & $21(6-70)$ & $26(3-70)$ & 0.36 & $18(0-66)$ & $24(0-66)$ \\
\hline $\begin{array}{l}\text { Hysterectomy after } \\
\text { embolization }\end{array}$ & & 4 & & & 10 \\
\hline
\end{tabular}

The values represent $n(\%)$ unless otherwise stated. *Comparing included women after embolization with included women after hysterectomy. **accr/incr/percr: accreta, increta, and percreta.

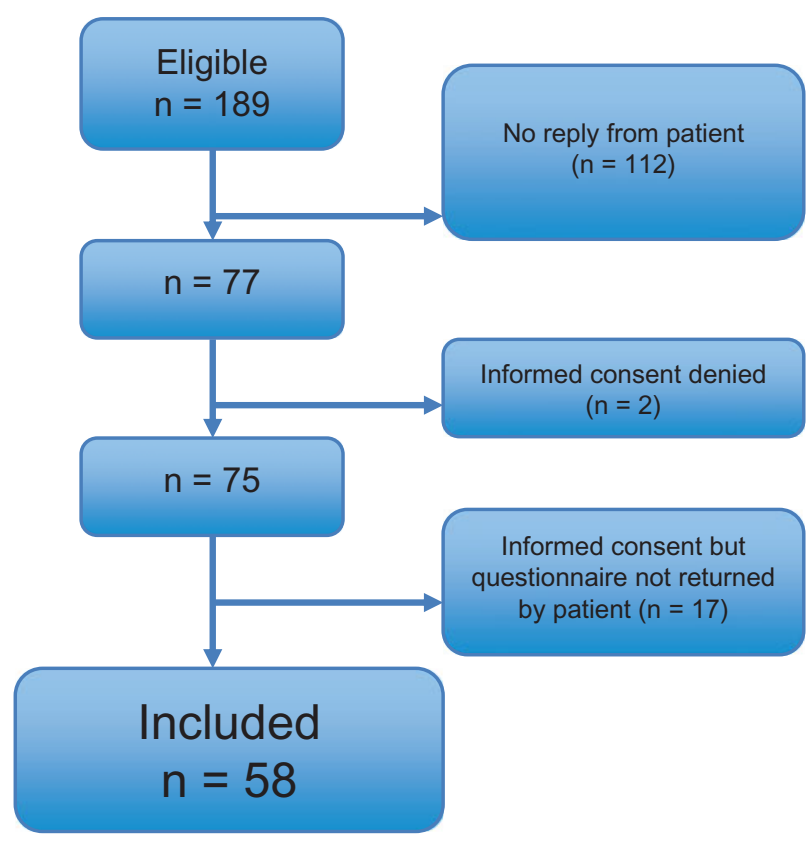

Figure 1. Selection and inclusion of women.

Compared to the gender-specific reference group, women scored better on dimension "physical functioning" and "pain" and worse on dimension "vitality". Compared to the age-specific reference group, women scored better on dimension "physical functioning" and "pain" and worse on dimension "vitality" and "social functioning".

Women who were treated with embolization scored better compared to women who were treated with hysterectomy on all dimensions and significantly better on dimensions: "pain" and "role limitations (due to physical problems)" (Figure 2).

\section{Partners}

Mean age of the partners was 34.5 years (spread: 29-41 years). Compared to their age-specific and gender-specific reference group, partners scored significantly better on dimensions: "physical functioning", "pain", "role limitations (due to emotional problems)", "role limitations (due to physical problems)", and "social functioning". Compared to the gender-specific reference group, partners scored better on dimension "general health perception". There were no significant differences between partners of women after embolization and partners of women after hysterectomy.

\section{B-IPQ (Table 3)}

The reported impact of the event reflected by dimension "consequences" is higher than the impact reported by patients of reference groups. In addition, women expected a shorter duration and experienced less personal control over the event than reference groups, as reflected by dimensions "timeline" and "personal control". Women in our study experienced less disease-related symptoms ("identity") and felt less concerned compared to patients with asthma or SLE.

Women treated with embolization scored significantly lower on dimensions "consequences" and 
Table 2. RAND-36 results of women (embolization and hysterectomy combined) compared to reference groups.

\begin{tabular}{|c|c|c|c|c|c|c|c|c|}
\hline & \multirow{3}{*}{$\begin{array}{l}\text { Included women } \\
(n=58) \text { mean (SD) }\end{array}$} & \multicolumn{6}{|c|}{ Reference groups } & \multirow{3}{*}{$\begin{array}{c}\text { Included partners } \\
(n=47-49) \text { mean }(S D)^{*}\end{array}$} \\
\hline & & \multicolumn{2}{|c|}{ Gender } & \multicolumn{2}{|c|}{ Age (35-44 years) } & \multicolumn{2}{|c|}{ Age (45-54 years) } & \\
\hline & & Ref value & $p$ values & Ref value & $p$ Values & Ref Value & $p$ Values & \\
\hline General health perception & $70.1(23.7)$ & 71.5 & 0.23 & 74.0 & 0.21 & 71.6 & 0.63 & $79.0(19.6)$ \\
\hline Physical functioning & $94.5(8.8)$ & 80.7 & 0.000 & 90.0 & 0.000 & 79.9 & 0.000 & $98.2(5.1)$ \\
\hline Change in health & $52.6(17.3)$ & 53.4 & 0.72 & 55.4 & 0.22 & 51.9 & 0.69 & $53.6(15.3)$ \\
\hline Mental health & $75.0(17.4)$ & 75.5 & 0.85 & 76.9 & 0.43 & 76.7 & 0.48 & $80.6(14.7)$ \\
\hline Pain & $91.9(17.6)$ & 80.0 & 0.000 & 83.8 & 0.000 & 80.5 & 0.000 & $96.0(9.1)$ \\
\hline Role limitations (emotional) & $87.4(29.8)$ & 82.5 & 0.22 & 83.6 & 0.34 & 82.2 & 0.19 & $98.0(8.1)$ \\
\hline Role limitations (physical) & $82.3(33.1)$ & 78.3 & 0.36 & 82.9 & 0.90 & 78.9 & 0.43 & $96.4(16.1)$ \\
\hline Social functioning & $81.7(23.0)$ & 86.1 & 0.15 & 88.0 & 0.04 & 86.1 & 0.15 & $96.2(8.9)$ \\
\hline Vitality & $60.5(20.9)$ & 66.3 & 0.04 & 67.5 & 0.01 & 67.1 & 0.02 & $70.6(15.0)$ \\
\hline
\end{tabular}

A higher score reflects a better outcome. * Reference values are only applicable for included women, not for partners.

Table 3. B-IPQ results of women (embolization and hysterectomy combined) compared to reference groups.

\begin{tabular}{|c|c|c|c|c|c|c|c|c|}
\hline & \multirow{3}{*}{$\begin{array}{l}\text { Included women } \\
(n=58) \text { mean (SD) }\end{array}$} & \multicolumn{6}{|c|}{ Reference groups } & \multirow{3}{*}{$\begin{array}{l}\text { Included partners } \\
\qquad(n=45-49) \\
\text { mean (SD)* }\end{array}$} \\
\hline & & \multicolumn{2}{|c|}{$\mathrm{MI}$} & \multicolumn{2}{|c|}{ Asthma } & \multicolumn{2}{|c|}{ SLE } & \\
\hline & & Ref value & $p$ Values & Ref value & $p$ Values & Ref value & $p$ Values & \\
\hline Consequences & $7.5(2.6)$ & 4.1 & 0.000 & 3.5 & 0.000 & 6.5 & 0.000 & $5.7(2.8)$ \\
\hline Timeline & $4.7(2.8)$ & 7.2 & 0.000 & 8.8 & 0.000 & 9.2 & 0.000 & $3.9(2.6)$ \\
\hline Personal control & $3.4(3.1)$ & 7.7 & 0.000 & 6.7 & 0.000 & 5.6 & 0.000 & $3.7(3.2)$ \\
\hline Treatment control & $8.22 .3)$ & 8.8 & 0.06 & 7.9 & 0.40 & $8.4(0.50)$ & 0.50 & $7.7(2.8)$ \\
\hline Identity & $3.2(3.1)$ & 3.1 & 0.79 & 4.5 & 0.002 & 6.0 & 0.000 & N/A \\
\hline Concern & $3.5(3.2)$ & 6.2 & 0.000 & 4.6 & 0.013 & 5.8 & 0.000 & $1.8(2.3)$ \\
\hline Emotional response & $4.1(3.3)$ & 4.2 & 0.86 & 3.5 & 0.16 & 5.8 & 0.000 & $2.6(2.8)$ \\
\hline Understanding & $7.2(3.2)$ & 8.0 & 0.05 & 6.5 & 0.13 & 6.8 & 0.40 & $7.2(2.6)$ \\
\hline
\end{tabular}

Ml: myocardial infarction; SLE: systemic lupus erythematosus.

A lower score reflects a better outcome. *Reference values are only applicable for included women, not for partners.

"timeline" and significantly higher on "treatment control" compared to women treated with hysterectomy.

\section{Partners}

B-IPQ scores indicated that partners of women who were treated with embolization felt less concerned and had more trust in embolization as a treatment modality compared to partners of women who were treated with hysterectomy.

\section{Drawings (Figure 3)}

The 46 peripartum uterus drawings (Drawing 1) had an average surface of 29.1 square $\mathrm{cm}$. This dropped significantly $(p<0.01)$ to 14.3 square $\mathrm{cm}$ in the followup drawings (Drawing 2, $n=38$ ), indicating a reduction in emotional impact of the event over time. The score on "degree of blood loss", "degree of damage to the uterus", and "psychological impact", ranging from 0 to 12 , dropped from 6.1 (Drawing 1) to 2.3 (Drawing 2) for women after embolization. In the hysterectomy group, the score dropped from 5.9 to 2.6. These results are consistent with results from other drawing studies in that the size of the drawn organs is reduced after the upsetting event has taken place [21,29-33]. The intraclass correlation coefficient between G. S. and
L. R. on Drawing 1 and Drawing 2 was 0.82 and 0.66 , respectively.

Neither drawing scores and B-IPQ scores nor drawing surfaces and B-IPQ scores correlated significantly.

\section{Survey}

The majority of women and partners (75\%) were satisfied with the hospital care provided. In general, women and partners highly appreciated personal attention, compassionate care, and time for questions and explanations. However, not all women appeared satisfied with the provided care as one woman explained: "Some health-care workers are born to this work, they are compassionate, sweet and understanding. Others are just making a living".

Several women advised more extensive follow-up (i.e. offering outpatient consultation 6 months after the event). Partners put into words that they missed information and attention during the event and felt lonely, insecure, and powerless.

On the basis of the responses, both patients and partners recognized the severity of the event; $58 \%$ of the women thought they were going to die compared to $72 \%$ of their partners. One woman illustrated: "I looked death in the eye". We found contradictory expressions of "benefit finding" as reflected by the 


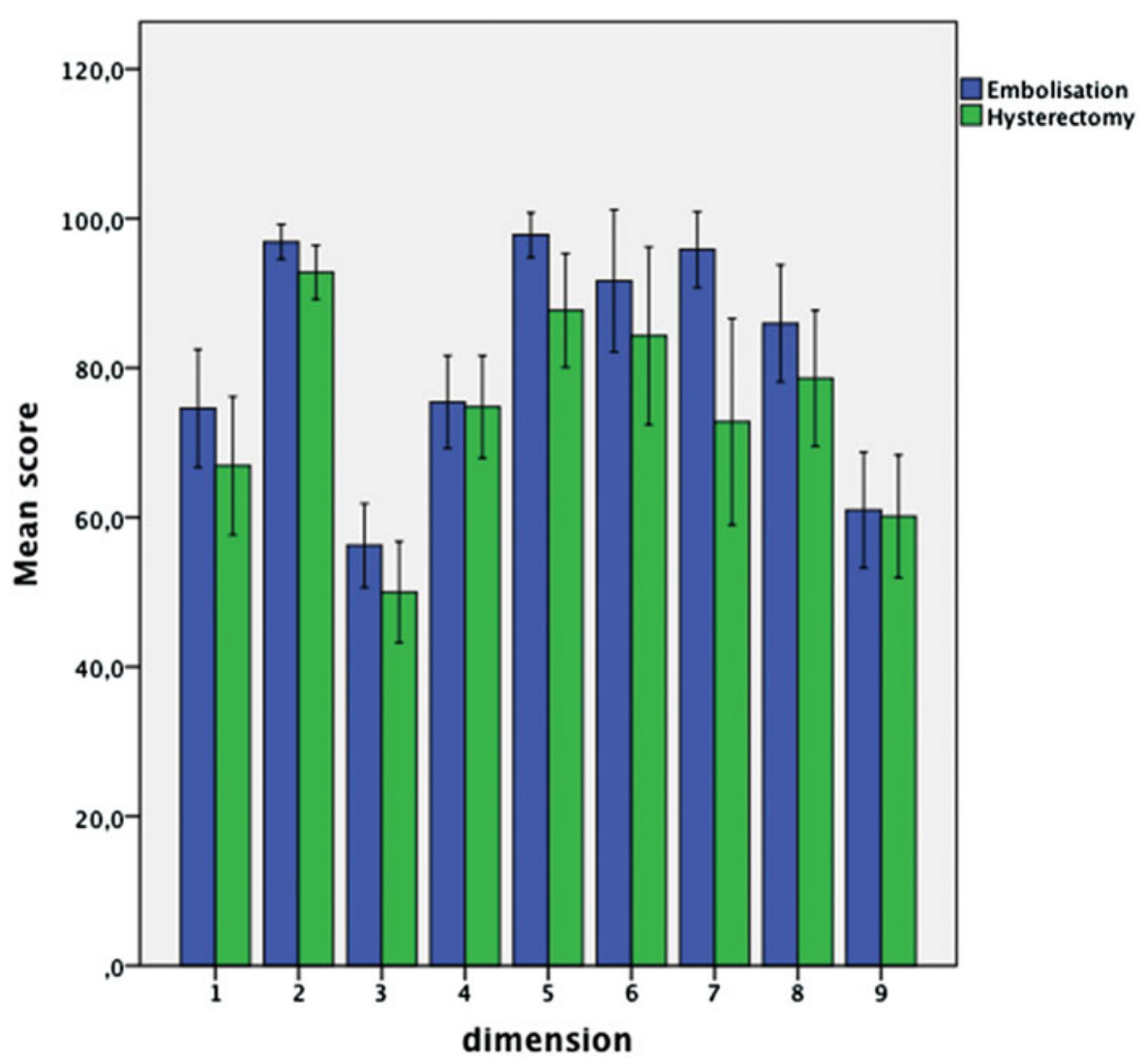

Figure 2. Mean scores (100 points scale) on RAND-36 dimensions, in women after embolization and women after hysterectomy*. 1. General health perception $(p=0.20)$, 2. Physical functioning $(p=0.06)$, 3. Change in health $(p=0.18), 4$. Mental health $(p=0.89), 5$. Pain $(p=0.016), 6$. Role limitations (due to emotional problems) $(p=0.36)$, 7. Role limitations (due to physical problems) $(p=0.003)$, 8. Social functioning $(p=0.22)$, 9. Vitality $(p=0.89)$. Error bars: $95 \%$ confidence interval. ${ }^{*}$ A higher score reflects a better outcome.

following quotes: "You realize what you have and what could have happened", to: "Twelve weeks of hospitalization did not bring me anything positive".

Women reacted extremely diverse concerning the impact of the loss of their uterus. The question: "Your uterus has been removed, what does this mean to you?" was answered using a VAS scale ranging from: "nothing" (0) to "disastrous" (10). The mean score was 4.1 with a SD of 3.7 and a range from 0.0 to 10.0.

Women who were treated with hysterectomy and desired more children $(n=18)$ scored significantly worse on the RAND-36 than women treated with hysterectomy who indicated their family as "complete".

\section{Discussion}

\section{Main findings}

Women in this study appear to have similar QOL compared to reference groups 6-9 years after the event. Women who were treated with embolization seem to have a slight advantage over women who were treated with hysterectomy in terms of QOL. This might be the consequence of the more invasive nature of hysterectomy and its associated loss of fertility. The results of the illness perception questionnaire showed that the impact of the event was high compared to reference groups. Women treated with embolization experienced less impact and a shorter duration of the event, and expected more effect of the treatment, compared to women treated with hysterectomy. The lower scores on B-IPQ dimension "timeline" by women treated with embolization probably reflect the short and treatable nature of the medical condition. Moreover, women who were treated with hysterectomy might realize they will never recover fully due to loss of fertility. This is especially true for women who desired more children and were treated with hysterectomy compared to women who were treated with hysterectomy and reported their family as "complete".

In general, one could say that a woman treated with embolization for $\mathrm{MOH}$ perceives the event as shorter, with more personal control and with less consequence compared to a woman treated with hysterectomy. This is reflected in the results of the RAND questionnaire with less reported pain and better physical functioning, which is compatible with the common sense model. 
6 G. van Stralen et Al.
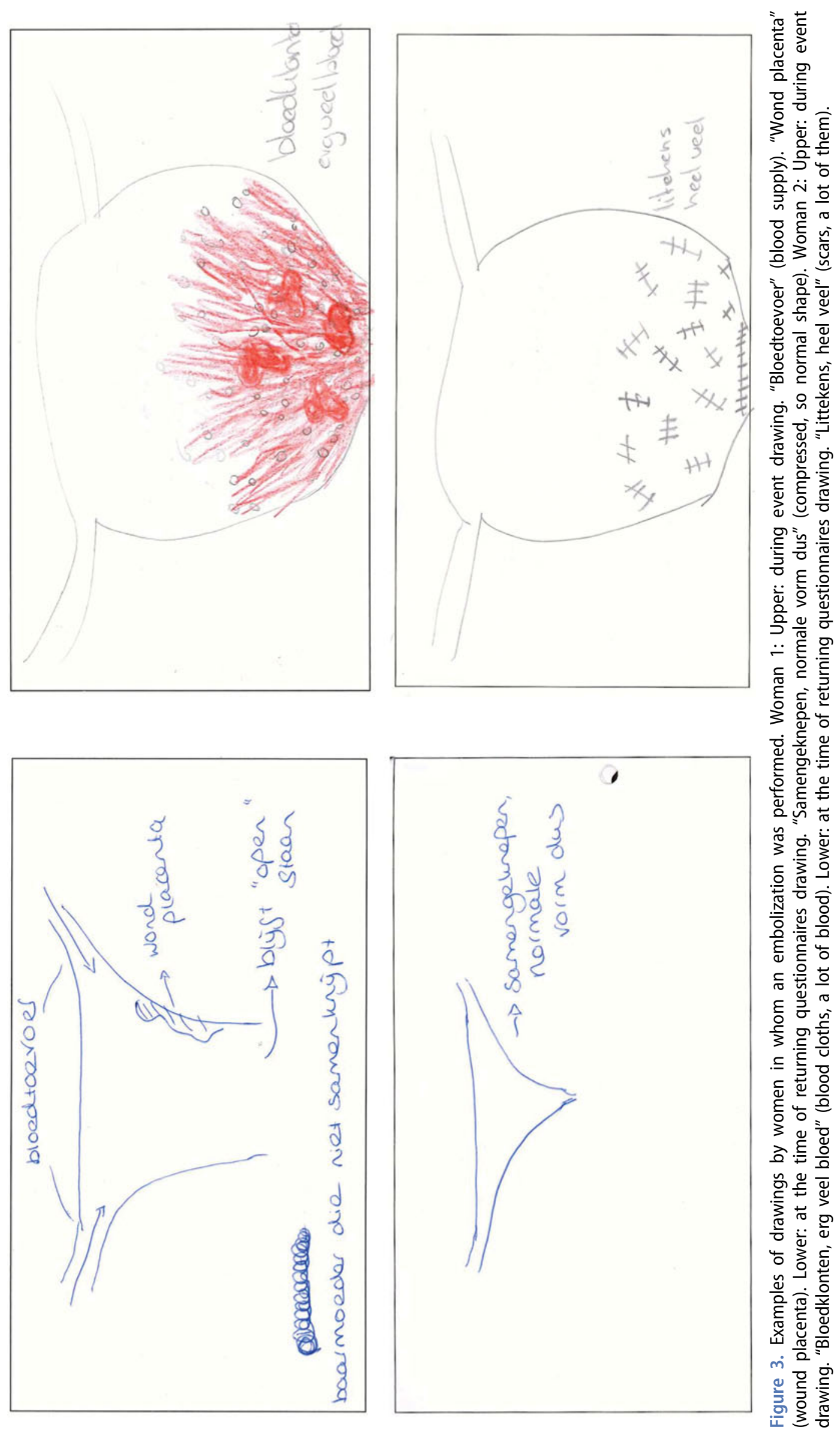
Partners scored better on $\mathrm{QOL}$ than reference groups provided by the RAND-36, which is reassuring. A possible explanation for the positive results of the partners in our study could be "benefit finding". This is supported by a meta-analysis of Hodges et al. on psychological stress of cancer patients and their caregivers (partners) which showed a positive correlation between couples, which means patients and caregivers experience the same level of psychological stress [34].

\section{Strengths and limitations}

The strength of this cohort study is the nationwide coverage and the fact that all women who met the inclusion criteria were identified. Unfortunately, only $31 \%$ of the eligible women could be included which is a limitation of the study. It is of note that clinical data relating to the women who did not respond were in a slightly better clinical condition. The results of this study, however, should be seen in the light of a relatively low response rate. As far as we know, this study gives the first results on QOL of partners of women who suffered from $\mathrm{MOH}$. The RAND-36 and the B-IPQ questionnaire provided reference groups do not fully match the characteristics of the women and their partners in this study. Although not optimal, the reference groups used in this study are the only and best available, predefined groups. Future research may benefit from a reference group of healthy couples who, for instance, experienced an uncomplicated birth on the same day, in the same hospital as included women who suffered $\mathrm{MOH}$. Although the drawings subjectively indicated recovery, we did not find the expected correlation between characteristics of the drawings and the B-IPQ scores. In addition, as described in the Introduction section, the expected correlation between B-IPQ scores and RAND-36 was moderate in this study. The maximum Pearson's correlation coefficient was 0.64 . This means that the less concerned or emotional a person is about the event, the better the general health perception is. In addition, the greater the emotional response, the more problems people experience with functioning (due to physical problems) and with social functioning.

As mentioned before, QOL is variable over time. Ideally, QOL is measured several times after the event. The results of this study may be influenced by the interval between the event and the completion of the questionnaires through recall-bias, benefit finding, and cognitive dissonance reduction.

\section{Interpretation}

QOL studies in women after $\mathrm{MOH}$ are small in number. A recent study of Prick et al. described $\mathrm{QOL}$ in the 6 weeks after PPH in women with or without blood transfusion [35]. Transfused women scored better on fatigue scales and marginally better on the RAND-36. Leung et al. reported on women after admission to an obstetric ICU in a 10-year retrospective cohort study of 50 women [36]. Unlike our findings, surviving women scored significantly lower on dimensions "physical functioning" and "pain" compared to healthy Chinese women living in Hong Kong. The difference in outcome between the Chinese and the women included in our study might be explained by the fact that $62 \%$ had other admission reasons than $\mathrm{MOH}$.

\section{Clinical implications}

In striving to restore or maintain $\mathrm{QOL}$ after $\mathrm{MOH}$ health-care providers should consider offering more extensive follow-up than the standard 6-week outpatient visit, which is routine in the Netherlands. This is recommended by several women and supported by those who were dissatisfied with the provided care (25\%) and the negative correlation between dimensions "concern" and "emotional response", and "general health perceptions". Offering women and partners consultations 6 or 12 months after the event might increase the chance of identifying the need for psychological help and might be preventive, as illustrated by a woman in whom hysterectomy was performed: "There were some loose strings. I wish I had made an appointment with my gynecologist after a year or so but it is hard to make such an appointment by oneself". In addition, we should keep partners informed during the absence of their wives in the operating theater. "We are doing everything possible and necessary and we will keep you informed" is better than an absence of any communication.

\section{Acknowledgements}

We thank the women and their partners for their collaboration in this study. We would like to acknowledge Prof. Sicco Scherjon MD for initiating the research on QOL after $\mathrm{MOH}$.

\section{Disclosure statement}

None of the authors report any conflict of interest. No funding was received for this study. There was no involvement of a pharmaceutical or other company. 


\section{References}

1. Zwart JJ, Dijk PD, van Roosmalen J. Peripartum hysterectomy and arterial embolisation for major obstetric haemorrhage: a 2-year nationwide cohort study in the Netherlands. Am J Obstet Gynecol 2009;201:1-7.

2. Ford JB, Roberts $C L$, Simpson JM, et al. Increased postpartum hemorrhage rates in Australia. Int J Gynaecol Obstet 2007;98:237-43.

3. Cameron CA, Roberts $\mathrm{CL}$, Olive EC, et al. Trends in postpartum haemorrhage. Aust N Z J Public Health 2006;30:151-6.

4. Robert $\mathrm{CL}$, Ford JB, Algert CS, et al. Trends in adverse maternal outcomes during childbirth: a populationbased study of severe maternal morbidity. BMC Pregn Childbirth 2009;9:7.

5. Callaghan WM, Kuklina EV, Berg CJ. Trends in postpartum hemorrhage: United States, 1994-2006. Am J Obstet Gynecol 2010;202:353.e1-6.

6. Bateman BT, Berman MF, Riley LE, Leffert LE. The epidemiology of postpartum haemorrhage in a large, nationwide sample of deliveries. Anesth Analg 2010; 10:1368-73.

7. Berg CJ, MacKay AP, Qin C, Callaghan WM. Overview of maternal morbidity during hospitalization for labor and delivery in the United States: 1993-1997 and 20012005. Obstet Gynecol 2009;113:1075-81.

8. Wen SW, Huang $L$, Liston $R$, et al. Severe maternal morbidity in Canada, 1991-2001. CMAJ 2005; 173:759-64.

9. Joseph KS, Rouleau J, Kramer MS, et al. Investigation of an increase in postpartum hemorrhage in Canada. BJOG 2007;114:751-9.

10. Al-Zirqi I, Vangen S, Forsen L, Stray-Pedersen B. Prevalence and risk factors of severe obstetric haemorrhage. BJOG 2008;115:1265-72.

11. Rossen J, Økland I, Nilsen OB, Eggebø TM. Is there an increase of postpartum hemorrhage, and is severe hemorrhage associated with more frequent use of obstetric interventions? Acta Obstet Gynecol Scand 2010;89:1248-55.

12. Knight $M$, Callaghan WM, Berg $C$, et al. Trends in postpartum hemorrhage in high resource countries: a review and recommendations from the International Postpartum Hemorrhage Collaborative Group. BMC Pregn Childbirth 2009;9:55.

13. van Stralen G, von Schmidt auf Altenstadt JF, Bloemenkamp KW, et al. Acta Obstet Gynecol Scand 2016;95:1104-10.

14. Arulkumaran $S$, Karosi M, Keith LG, Lalonde AB, BLynch $C$, eds. A comprehensive textbook of postpartum hemorrhage. 2nd ed. London: Sapiens Publishing Ltd.; 2012.

15. van Stralen G, van Stralen-Ruijten LLM, Spaargaren CF, et al. Good quality of life after emergency embolisation in postpartum haemorrhage. J Psychosom Obstet Gynaecol 2010;31:285-8. Erratum in: J Psychosom Obstet Gynaecol 2011;32:52.

16. Mock S, Boerner K. Sense making and benefit finding among patients with amyotrophic lateral sclerosis and their primary caregiver. J Health Psychol 2010; $15: 115-21$.
17. Petrie KJ, Buick DL, Weinman J, Booth RJ. Positive effects of illness reported by myocardial infarction and breast cancer patients. J Psychosom Res 1999; 47:537-43.

18. Schipper H, Clinch JJ, Olweny CLM, Quality of life studies: definitions and conceptual issues. In: Spilker B, ed. Quality of life and pharmacoeconomics in clinical trials. 2nd ed. Philadelphia (PA): Lippincott-Raven Publishers; 1996:11-23.

19. Kaptein AA, Scharloo M, Fischer MJ, et al. Illness perceptions and COPD: an emerging field for COPD patient management. J Asthma 2008;45:625-9.

20. Leventhal EA. Aging and the perception of illness. Res Aging 1984;6:119-35.

21. Kaptein AA, Schoones JW, Fischer MJ, et al. Illness perceptions in women with breast cancer - a systematic literature review. Curr Breast Cancer Rep 2015; 7:117-26.

22. Leventhal $H$, Brissette I, Leventhal EA, The common sense model of self-regulation of health and illness. In: Cameron LD, Leventhal $\mathrm{H}$, eds. The self-regulation of health and illness behaviour. London: Routledge; 2003:43-57.

23. Zwart JJ, Richters JM, Öry F, et al. Severe maternal morbidity during pregnancy, delivery and puerperium in the Netherlands: a nationwide population-based study of 371,000 pregnancies. BJOG 2008;115:842-50.

24. van der Zee KI, Sanderman R. Het meten van de gezondheidstoestand met de RAND-36: een handleiding [Measuring health using the RAND-36: manual]. Groningen: Noordelijk Centrum voor Gezondheidsvraagstukken [Northern centre for health issues], 1993.

25. Ware JE, Sherbourne CD. The MOS 36-item short-form health survey (SF-36). I. Conceptual framework and item selection. Med Care 1992;30:473-81.

26. Weinman J, Petrie KJ, Moss-Morris R, Horne R. The Illness Perception Questionnaire: a new method for assessing the cognitive representation of illness. Psychol Health 1996;11:43-52.

27. Broadbent E, Petrie KJ, Main J, Weinman J. The Brief Illness Perception Questionnaire. J Psychosom Res 2006;60:631-7.

28. Daleboudt GM, Broadbent E, Berger SP, Kaptein AA. Illness perceptions in patients with systemic lupus erythematosus and proliferative lupus nephritis. Lupus 2011;20:290-8.

29. Broadbent E, Ellis CJ, Gamble G, Petrie KJ. Changes in patient drawings of the heart identify slow recovery after myocardial infarction. Psychosom Med 2006;68:910-13.

30. Reynolds L, Broadbent E, Ellis CJ, et al. Patients' drawings illustrate psychological and functional status in heart failure. J Psychosom Res 2007; 63:525-32.

31. Tiemensma J, Daskalakis NP, van der Veen E, et al. Drawings reflect a new dimension of the psychological impact of long-term remission of Cushing's syndrome. J Clin Endocrinol Metab 2012;97:3123-31.

32. Kaptein AA, Zandstra $T$, Scharloo $M$, et al. 'A time bomb ticking in my head': drawings of inner ears by patients with vestibular schwannoma. Clin Otolaryngol 2011;36:183-4. 
33. Tiemensma J, Pereira AM, Romijn JA, et al. Persistent negative illness perceptions despite long-term biochemical control of acromegaly: novel application of the drawing test. Eur J Endocrinol 2015;172:583-93.

34. Hodges LJ, Humphris GM, Macfarlane G. A metaanalytic investigation of the relationship between the psychological distress of cancer patients and their carers. Soc Sci Med 2005;60:1-12.
35. Prick BW, Jansen AJG, Steegers EAP, et al. Transfusion policy after severe postpartum haemorrhage: a randomised non-inferiority trial. BJOG 2014;121:1005-14.

36. Leung NY, Lau AC, Chan KK, Yan WW. Clinical characteristics and outcomes of obstetric patients admitted to the intensive care unit: a 10-year retrospective review. Hong Kong Med J 2010;16:18-25.

\section{Current knowledge on the subject}

- Women who were treated with embolization of the uterine artery for $\mathrm{MOH}$ show good $\mathrm{QOL}$, years after the event.

- Although MOH has a big impact, good QOL could be the result of "benefit finding".

- Illness perceptions influence QOL.

\section{What this study adds}

- Women who were treated with embolization of the uterine artery for $\mathrm{MOH}$ show better $\mathrm{QOL}$ than women who were treated with hysterectomy.

- Partners of women who experienced $\mathrm{MOH}$ have comparable QOL as reference groups.

- More extensive follow-up may be beneficial for some couples. 